\title{
Bubble, Bubble, Bubble
}

\author{
Marvin L. Birnbaum, MD, PhD
}

I think this piece will belp to boil thy pot. John Wolcot: The Bard Complementeth Mr. West. (c. 1790) Probably the origin of the term "pot-boiler".

Glory is excellent, but will not make the national pot boil.

Carlyle: Frederick the Great, xvi,2; vi, 151.

It happened again! This time it happened for me at the Second Pan American Congress for Disaster and Emergency Medicine convened in Mexico City. The hosts were wonderful and the people who attended the Congress were the same special persons I have had the privilege of associating with for the 11 years that I have served as the Editor of this Journal. Different people, but the same type of persons. The same compassionate, caring persons who attend these Congresses only because they care.

Judging from my observations, most of these attendees left the Congress at its conclusion (and they did stay until the very end) carrying with them the same feeling I had about the persons involved in our special science. On leaving, we felt rejuvenated and our attitudes towards what we do were reinforced. There were no turf battles; there was no jealousy, no competition, no imposition; the Congress was pervaded by excitement at sharing, and sharing we did. We shared our experiences and concerns and learned from the experiences of others. But, individual by individual, few of us have any substantial experience. Unlike other special areas of Medicine in which experiences run high and we learn by doing things over and over, in Disaster/Humanitarian Medicine, this is not possible. We must share our experiences and learn from each other.

The Program Committee, led by Dr.
Felipe Cruz-Vega, sought to extend further the pattern established at the $1 \mathrm{st}$ Pan-American Congress convened in Costa Rica in 1998. The Programme in Mexico City was comprehensive, wellcoordinated, and had remarkable breadth with notable speakers who addressed topics cogent to the development of Disaster, Prehospital, Emergency, and Humanitarian Medicine in the Region. The Programme was supported by many Mexican medical organizations, with the Pan-American Health Organization, and was provided in conjunction with the World Association for Disaster and Emergency Medicine (WADEM). The Congress was attended by more than 800 persons, an attendance almost double that for the 1st Pan-American Congress in San Jose in 1998. The participants came mostly from Latin America, but included were participants from Europe and the northern part of the Americas.

The Mexico City Congress now is testimony that we are coming together on a regional basis. But even more significantly, this Congress served as a focal point for the organization and actualization of the Pan-American Society for Disaster and Emergency Medicine. The Society has incorporated, has developed bylaws, and offers an open structure for all of the practitioners in Latin America. Together, it was possible to conceive of the Congress, plan it, and implement it with a remarkably short lead-time. And furthermore, under the leadership of Dr. Cruz-Vega, the newly formed PanAmerican Society has become part of the family by affiliating with the WADEM.

This process follows the motivation and the model previously established by the formation of the Nordic Society for Disaster Medicine. The Nordic Society has produced three Regional Congresses so far, and the 4th will be convened in Copenhagen, Denmark late in August. And, this model is being followed elsewhere in the World community.

But, the significance of all of these Regional Congresses portends an important development: the realm of Disaster, Prehospital, Emergency, and Humanitarian Medicine is coming together - much like a good stew: as they cook, the many individual ingredients blend together into something much better than each of the ingredients alone. Yet, such combinations differ in accordance to the culture of the Region in which they are created. There are regional issues to be addressed as well as those that have no borders. Some ingredients are common to all and should be discussed at a worldwide level and shared at the regional level. Others are specific to the region and relate to the specific set of cultures in which such catastrophes occur. It has been wise for WADEM to help to create an environment in which regional issues come to the forefront through its encouragement of regional congresses as well as its world congresses. Regional Congresses seek to integrate what has been learned from disasters worldwide with those issues specific to the region. They enhance the external validity of what has been learned in the larger scale. Both are equally important in the development of our science.

Regardless of the level of the Congress (local, regional, worldwide), it is the people that make the difference: very special folks who give to each other and learn from others. Not even the differences in languages divert these people from communicating their concern for humanity. I hope we never lose this very special characteristic of our new discipline. 
Several of these Regional Congress are imminent: the 4th Nordic Congress will convene in Copenhagen in late August-September (Abstracts included in this issue), the 1st Military-Disaster Congress for the Baltic Countries convenes in Portoroz, Slovenia in September, and the 5th Asia-Pacific Congress will gather in Vancouver, British Columbia Canada later in September. I suggest you try to attend one of these regional congresses, for

Editor's Note: The translations of the abstracts of the scientific papers in this issue did not arrive in time to meet the deadlines for this issue. They will be published in the next issue of Prehospital and Disaster Medicine, Volume 15, Number 3: July-September 2000. there still is time to participate. Come share your expe riences and thoughts. Join this very special group of per sons who care so much about this world, who strive dail to make this world a better place for all of its inhabi tants, who always are there when needed - the ver definition of friends. Come watch the pot bubble awa! and become part of this special and unique creation.

Would the cook were of my mind!

Shakespeare: Much Ado About Nothing, Act ii, sc 1,1260

Editor's Note: The next issue of Prehospital and Disaster Medicine, Volume 15, Number 3: July-September 2000 will contain the abstracts for the 5th Asia-Pacific Conference on Disaster Medicine to be convened in Vancouver, British Columbia Canada, 27-30 September 2000. In excess of 100 abstracts by scientists from more than 20 countries have been accepted by the Scientific Committee for presentation at this Conference. (see: http://www.safety.ubc.ca/5APCDM/index.html) 